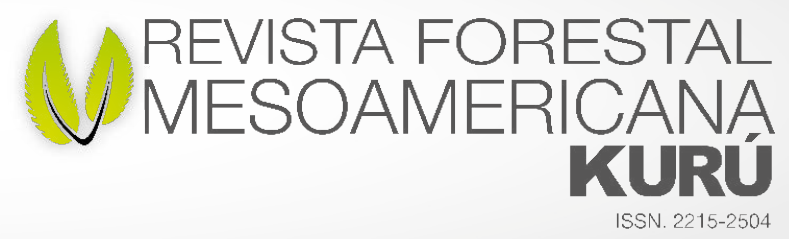

\title{
La ciencia e investigación en los tiempos de crisis
}

Juan Carlos Valverde

Durante el proceso evolutivo humano, se ha generado una gran cantidad de avances tecnológicos y científicos a partir de la investigación, análisis y entendimiento de los fenómenos ambientales y sociales. La investigación en muchos casos se ha relacionado con mejora de la calidad de vida, erradicación de enfermedades o creación de tecnologías que permitan un manejo sustentable de los recursos naturales.

En la historia de la humanidad, la investigación se ha usado con múltiples perspectivas, desde un uso bélico, a pacífico, sanitario, cultural y de manejo de recursos naturales que ha tomado un importante auge en el último siglo. Conforme la tecnificación de la sociedad aumente, la demanda de recursos naturales se incrementará exponencialmente; el desarrollo de economías emergentes ha incidido en creación de megalópolis, producción en serie gran cantidad de insumos o materiales y una constante demanda de alimentos y bienes; aspecto en los cuales la ciencia ha tenido que crear y desarrollar nuevas técnicas, tecnologías y conocimientos para mejorar el uso de los recursos disponibles.

Sin embargo, la ciencia no es independiente a los tiempos de crisis financiera. Cuando se da una contracción de mercados y desaceleración de economías, el área de la ciencia es de las más afectadas, debido a que muchos países la consideran como un área "no primordial", en comparación a educación, seguridad o salud; por tanto, el recorte de presupuestos tendea ser importante. Se impacta negativamente en las investigaciones y desarrollos tecnológicos que mejoren la calidad social. En caso Costa Rica en los últimos años ha habido una desaceleración científica, producto a la crisis fiscal la cual ha incidido en congelación de becas, recorte de plazas científicas y presupuestos estrechos a los proyectos existentes.

Ante tal situación, los investigadores deben tomar decisiones y acciones que les permitan mantener sus investigaciones, en el corto plazo se deben reformular los proyectos en forma tal que optimicen los recursos actuales incrementando el impacto a las áreas o sectores de estudio, se debe adoptar modelos dinámicos en los que la investigación no se limite a "artículos científicos" sino que el factor extensión sea complementario y se transfieran los conocimientos generados, también, se debe adoptar búsqueda de recursos internacionales e investigaciones conjuntas con universidades, instituciones o entes de otros países con ello generar un canal financiero y conocimiento que posibiliten el desarrollo de investigaciones financiadas en el tiempo.

Se debe tomar una actitud consciente, de que investigar no es un tema romántico, o sublime en que se hará un aporte totalmente nuevo; sino, se debe generar una mentalidad activa y dinámica y se piense un impacto real a la sociedad y ambiente de lo que se va generar. Debemos crear líneas de trabajo en el tiempo que permitan tener claro que tipo de problemáticas nacionales deben ser solucionadas y a partir de las cuales los investigadores propongan proyectos que busquen su solución de forma integral y en la cual la innovación, interrelación profesional. Conforme garanticemos una investigación adaptiva a las crisis podremos continuar las tendencias de mejora de vida y reactivación científica la cual en el tiempo se puede transformar en una mejora en condiciones y recursos económicos. Por tanto, la crisis debe ser vista como una oportunidad de mejora e incremento de habilidades de gestión financiera y uso de recursos en el tiempo. 